\title{
Early and Late Assessment of Stenosis Geometry After Coronary Arterial Stenting
}

\author{
JACQUES PUEL, MD, YVES JUILIERE, MD, MICHEL E. BERTRAND, MD, \\ ANTHONY F. RICKARDS, MD, ULRICH SIGWART, MD, \\ and PATRICK $W$. SERRUYS, MD
}

\begin{abstract}
Early and late modifications of stenosis geometry after stenting of coronary arteries were assessed. Morphologic changes were evaluated by quantitative coronary anglography (automated edge-detection) and theoretical pressure drop across the dilated and stented stenosis was calculated from the Poiseuille formula, with turbulent resistances assuming a coronary blood flow of 1 or $3 \mathrm{ml} / \mathrm{s}$. Eleven patlents (ages 41 to 69 years, mean 55) were studied before and after angioplasty, and immedlately after stent implantation. The stented coronary artery was the left anterior descending artery in 9 patients and the left circumflex in 2. Following stent implantation, an additional increase in minimal luminal cross-
\end{abstract}

sectional area of the dilated vessel was observed, suggesting that the self-expanding stainless-steel endoprosthesis used had a dilating function in addition to its stenting role. Repeat angiography in 6 patlents 3 months after stent implantation showed a decrease in the minimal luminal cross-sectional area without a significant change in theoretic pressure decrease. This slight reduction in vessel caliber had no hemodynamically significant repercussions. Thus, stenting of coronary arteries following dilatation is a potentially valuable technique for preventing both abrupt closure and late reduction in lumen diameter.

(Am J Cardiol 1988;61:546-553)
A 1though other techniques-pharmacologic, ${ }^{1}$ mechanical and thermal ${ }^{2,3}$ - are currently under investigation, intravascular stenting of the dilated vessels has been proposed as an alternative approach for preventing late restenosis after percutaneous transluminal coronary angioplasty (PTCA). Different prostheses have been developed and tested in animal experiments ${ }^{4-10}$ and, recently, intravascular stents have been implanted in patients. ${ }^{11}$ The endoprosthesis used in this open clinical trial consists of a self-expanding stainless-steel mesh that exerts a radial force on the

From the Department of Clinical and Experimental Cardiology, CHRU, Rangueil, Toulouse, France; Catheterization Laboratory and Laboratory for Clinical and Experimental Image Processing, Thoraxcenter, Rotterdam, The Netherlands; Department of Cardiology, Hôpital Cardiologique, Lille, France; Department of Clinical Measurement, National Heart Institute, London, United Kingdom; and Division of Cardiology, Department of Medicine, Centre Hospitalier Universitaire de Vaudois, Lausanne, Switzerland. Manuscript received July 9, 1987; revised manuscript received and accepted October 27, 1987.

Address for reprints: Patrick W. Serruys, MD, PhD, Catheterization Laboratory and Laboratory for Clinical and Experimental Image Processing, Thoraxcenter, Erasmus University, P. O. Box 1738, 3000 DR Rotterdam, The Netherlands. vascular wall. So far, there are no quantitative angiographic data indicating whether the endoluminal prosthesis affects the immediate anatomic result of PTCA. On the other hand, because animal experiments have shown a neointimal proliferation totally encasing stent wires within a few weeks, ${ }^{8-10}$ it is crucial to demonstrate that the stenotic geometry of the human stented artery does not deteriorate at short-term follow-up.

This study assesses early and delayed modifioations in stenotic geometry by quantitative coronary angiography after stenting of coronary arteries in 11 patients.

Study population: The 11 patients ranged in age from 41 to 69 years (mean 55) and 8 were men. They were treated and investigated in the 3 following centers: Department of Clinical and Experimental Cardiology, CHRU Rangueil, Toulouse, France (patients 6 11); Catheterization Laboratory, Thoraxcenter, Rotterdam, The Netherlands (patients 1-3) and Department of Cardiology, Hospital Cardiologique, Lille, France (patients 4-5). Informed consent was obtained from each patient before the intervention. The endoprosthesis used in this study was provided by Medinvent SA. The dilated and stented coronary artery was the left anterior descending artery in 9 patients and the left circumflex artery in 2 . This series of 11 patients includ- 
TABLE I Morphologic Results Immediately After Stenting and Three Months Later

\begin{tabular}{|c|c|c|c|c|c|c|c|c|}
\hline & $P t$ & $\begin{array}{c}\text { Extent } \\
\text { Obstruction (mm) }\end{array}$ & $\begin{array}{c}\text { Obstruction } \\
\text { Diameter (mm) }\end{array}$ & $\begin{array}{c}\text { Minimal } \\
\text { Cross-Sectional } \\
\text { Area }\left(\mathrm{mm}^{2}\right)\end{array}$ & $\begin{array}{l}\text { Diameter of } \\
\text { Stenosis (\%) }\end{array}$ & $\begin{array}{c}\text { Area of } \\
\text { Stenosis }(\%)\end{array}$ & $\begin{array}{c}\text { Reference } \\
\text { Diameter (mm) }\end{array}$ & $\begin{array}{l}\text { Reference } \\
\text { Area }\left(\mathrm{mm}^{2}\right)\end{array}$ \\
\hline & Pre-P & 7.1 & 0.4 & 0.1 & 82 & 96 & 2.6 & 5.6 \\
\hline & Post-P & 6.1 & 1.8 & 2.6 & 34 & 56 & 2.7 & 5.8 \\
\hline & Post-S & 5.3 & 2.0 & 3.2 & 27 & 46 & 2.8 & 6.1 \\
\hline & Pre-P & 8.2 & 0.7 & 0.4 & 75 & 94 & 2.8 & 6.0 \\
\hline & Post-P & 4.5 & 2.2 & 3.7 & 23 & 40 & 2.8 & 6.2 \\
\hline & Post-S & 5.4 & 2.3 & 4.3 & 22 & 39 & 3.0 & 7.2 \\
\hline & Pre-P & 6.2 & 1.1 & 0.9 & 56 & 81 & 2.4 & 4.7 \\
\hline & Post-P & 3.6 & 1.6 & 2.0 & 37 & 61 & 2.5 & 5.2 \\
\hline & Post-S & 3.8 & 2.5 & 5.0 & 10 & 19 & 2.8 & 6.3 \\
\hline & Pre-P & 5.5 & 0.7 & 0.4 & 73 & 93 & 2.5 & 5.0 \\
\hline & Post-P & 5.1 & 1.5 & 1.8 & 41 & 66 & 2.6 & 5.3 \\
\hline & Post-S & 4.9 & 2.2 & 3.7 & 17 & 32 & 2.6 & 5.4 \\
\hline & Pre-P & 6.9 & 1.1 & 1.1 & 61 & 83 & 2.8 & 6.3 \\
\hline & Post-P & 6.4 & 1.7 & 2.3 & 35 & 57 & 2.6 & 5.5 \\
\hline & Post-S & 6.3 & 1.6 & 2.1 & 40 & 64 & 2.7 & 5.9 \\
\hline \multirow{4}{*}{$\begin{array}{r}6 \mathrm{~F} \\
\mathrm{~F} \\
\mathrm{~F}\end{array}$} & Pre-P & 6.2 & 0.9 & 0.7 & 67 & 88 & 3.0 & 6.9 \\
\hline & Post-P. & 5.2 & 2.1 & 3.5 & 21 & 37 & 2.6 & 5.5 \\
\hline & Post-S & 6.2 & 2.4 & 4.5 & 13 & 24 & 2.8 & 6.0 \\
\hline & 3 Mths & 8.6 & 1.9 & 2.9 & 30 & 51 & 2.7 & 6.1 \\
\hline \multirow{4}{*}{$\begin{aligned} 7 \mathrm{~F} \\
\mathrm{~F} \\
\mathrm{~F}\end{aligned}$} & Pre-P & 8.1 & 1.6 & 2.0 & 49 & 74 & 3.1 & 7.7 \\
\hline & Post-P & 6.1 & 1.9 & 2.8 & 24 & 42 & 2.5 & 4.9 \\
\hline & Post-S & 7.0 & 2.8 & 6.2 & 13 & 24 & 3.2 & 8.2 \\
\hline & 3 Mths & 8.5 & 2.3 & 4.4 & 26 & 44 & 3.1 & 7.8 \\
\hline \multirow{4}{*}{8} & Pre-P & 8.6 & 1.5 & 1.8 & 45 & 70 & 2.8 & 6.2 \\
\hline & Post-P & 10.0 & 1.8 & 2.7 & 38 & 61 & 3.0 & 7.0 \\
\hline & Post-S & 9.4 & 2.3 & 4.3 & 23 & 40 & 3.0 & 7.3 \\
\hline & 3 Mths & 10.8 & 2.3 & 4.4 & 25 & 43 & 3.1 & 7.8 \\
\hline \multirow{4}{*}{$9 F$} & Pre-P & 10.0 & 1.6 & 1.9 & 54 & 79 & 3.4 & 9.3 \\
\hline & Post-P & 10.2 & 1.7 & 2.3 & 44 & 69 & 3.0 & 7.3 \\
\hline & Post-S & 8.7 & 2.0 & 3.3 & 39 & 62 & 3.4 & 8.9 \\
\hline & 3 Mths & 10.3 & 1.8 & 2.7 & 46 & 70 & 3.4 & 8.9 \\
\hline \multirow{4}{*}{$\begin{array}{r}10 \mathrm{P} \\
\mathrm{P} \\
\mathrm{P} \\
3\end{array}$} & Pre-P & 5.6 & 0.8 & 0.5 & 68 & 89 & 2.6 & 5.3 \\
\hline & Post-P & 4.9 & 1.7 & 2.6 & 31 & 52 & 2.5 & 5.1 \\
\hline & Post-S & 7.2 & 2.7 & 6.0 & 15 & 28 & 3.3 & 8.8 \\
\hline & 3 Mths & 6.3 & 1.9 & 3.0 & 37 & 61 & 3.1 & 7.8 \\
\hline \multirow{4}{*}{$\begin{aligned} 11 \mathrm{P} \\
\mathrm{P} \\
\mathrm{F} \\
3\end{aligned}$} & Pre-P & 7.6 & 2.0 & 3.1 & 44 & 69 & 3.6 & 10.1 \\
\hline & Post-P & 8.9 & 2.1 & 3.4 & 36 & 59 & 3.2 & 8.2 \\
\hline & Post-S & 7.5 & 2.4 & 4.9 & 33 & 55 & 3.5 & 9.9 \\
\hline & 3 Mths & 10.9 & 2.0 & 3.2 & 42 & 65 & 3.5 & 9.4 \\
\hline \multirow{4}{*}{$\begin{array}{l}\text { Mear } \\
\pm S E\end{array}$} & an Pre-P (11) & $7.3 \pm 0.4$ & $1.1 \pm 0.1$ & $1.2 \pm 0.3$ & $61 \pm 4$ & $83 \pm 3$ & $2.9 \pm 0.1$ & $6.6 \pm 0.5$ \\
\hline & E Post-P (11) & $\begin{array}{l}6.4 \pm 0.7 \text { 员 } \\
6.5 \pm 0.5\end{array}$ & 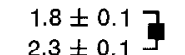 & $\begin{array}{l}2.7 \pm 0.2 \\
4.3 \pm 0.4\end{array}$ & $\begin{array}{l}33 \pm 2 \\
23+3\end{array}$ & $\begin{array}{r}54 \pm 37 \\
39 \pm 5\end{array}$ & $\left.\begin{array}{l}2.7 \pm 0.1 \\
3.0 \pm 0.1\end{array}\right\}$ & $\left.\begin{array}{l}6.0 \pm 0.3 \\
7.3 \pm 0.4\end{array}\right\}$ \\
\hline & $\begin{array}{l}\text { Post-S (11) } \\
\text { Post-S (6) }\end{array}$ & $\begin{array}{l}6.5 \pm 0.5 \\
7.7 \pm 0.5\end{array}$ & $\begin{array}{l}2.3 \pm 0.1 \\
2.4 \pm 0.17\end{array}$ & $\begin{array}{l}4.3 \pm 0.4] \\
4.9 \pm 0.47\end{array}$ & $23 \pm 47$ & $\begin{array}{l}39 \pm 5-7 \\
39 \pm 7\end{array}$ & $\begin{array}{l}3.0 \pm 0.1 \\
3.2 \pm 0.1 \text { 子 }\end{array}$ & $8.2 \pm 0.5$ ב \\
\hline & 3 Mths (6) & $9.2 \pm 0.79$ & $2.0 \pm 0.19$ & $3.4 \pm 0.3\}$ & $34 \pm 3\rfloor$ & $56 \pm 5\}$ & $3.1 \pm 0.1 \mathrm{~J}$ & $8.0 \pm 0.5 \square$ \\
\hline
\end{tabular}

$\square=$ not significant; $\bullet=p<0.05 ; 0=p<0.01 ; \boldsymbol{\square}=p<0.005$.

Mths $=$ months; $\mathrm{P}=\mathrm{PTCA} ; \mathrm{S}=$ stent; $\mathrm{SE}=$ standard error.

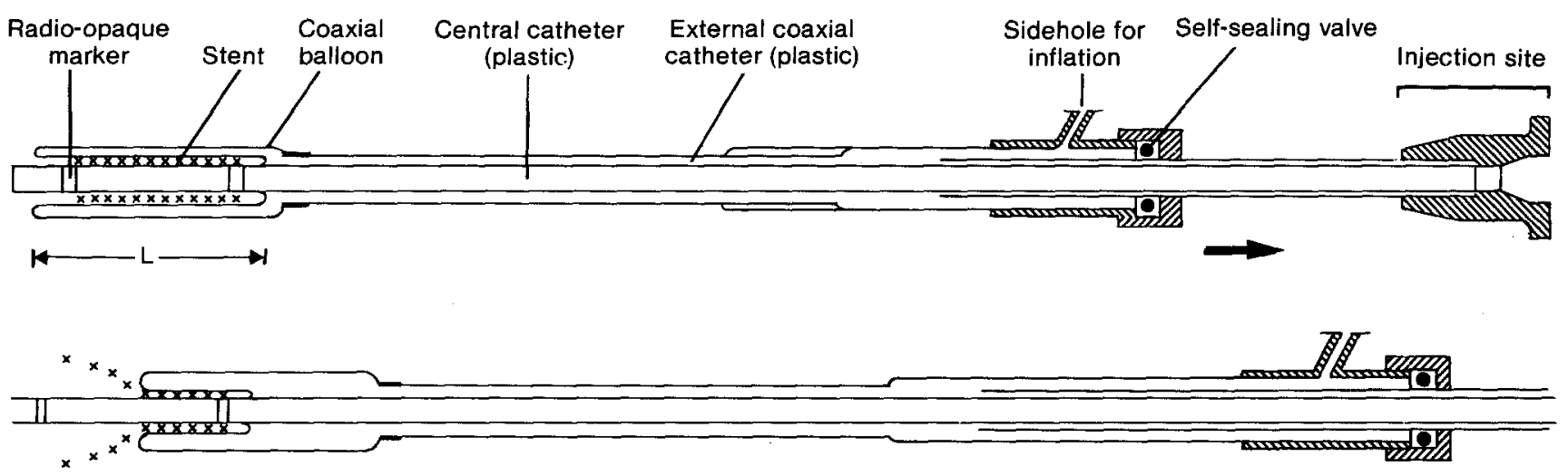

FIGURE 1. Longitudinal section of the stent delivery catheter showing the "constrained" stent surrounded by the coaxial balloon. Following inflation of the balloon, the outer sheath of the coaxial system is retracted (arrow) to allow the stent to expand within the arterial lumen. 

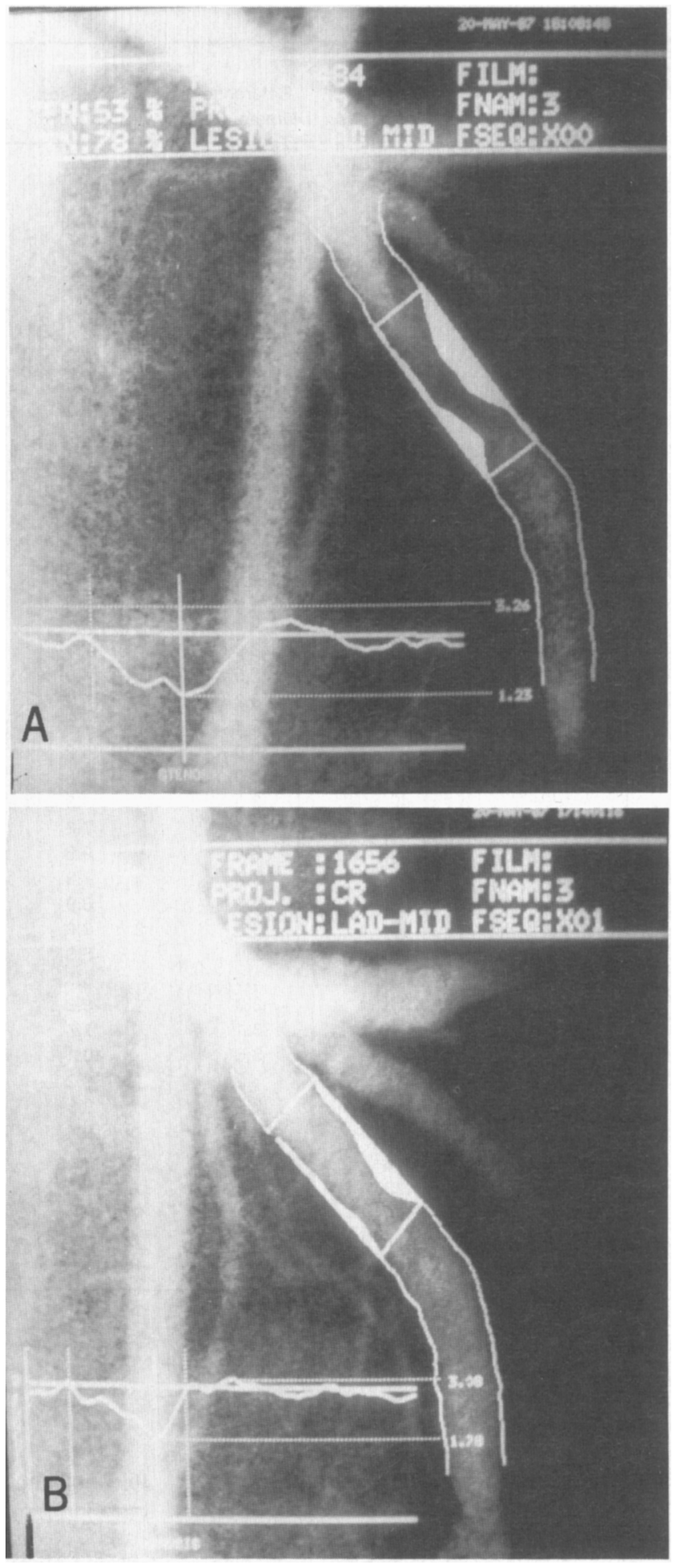

ed the first 6 consecutive patients who had an ondoprosthesis implanted in Toulouse for secondary prevention of restenosis and the first 5 patients with implants for primary prevention of restenosis in the pilot phase of a multicenter trial (Coronary Artery Stent Implant Study [CASIS]]. No coronary spasm occurred at the time of endoprosthesis implantation. In patient 7 , a transient decrease from 3.1 to $2.5 \mathrm{~mm}$ in the reference diameter was observed immediately after the di-

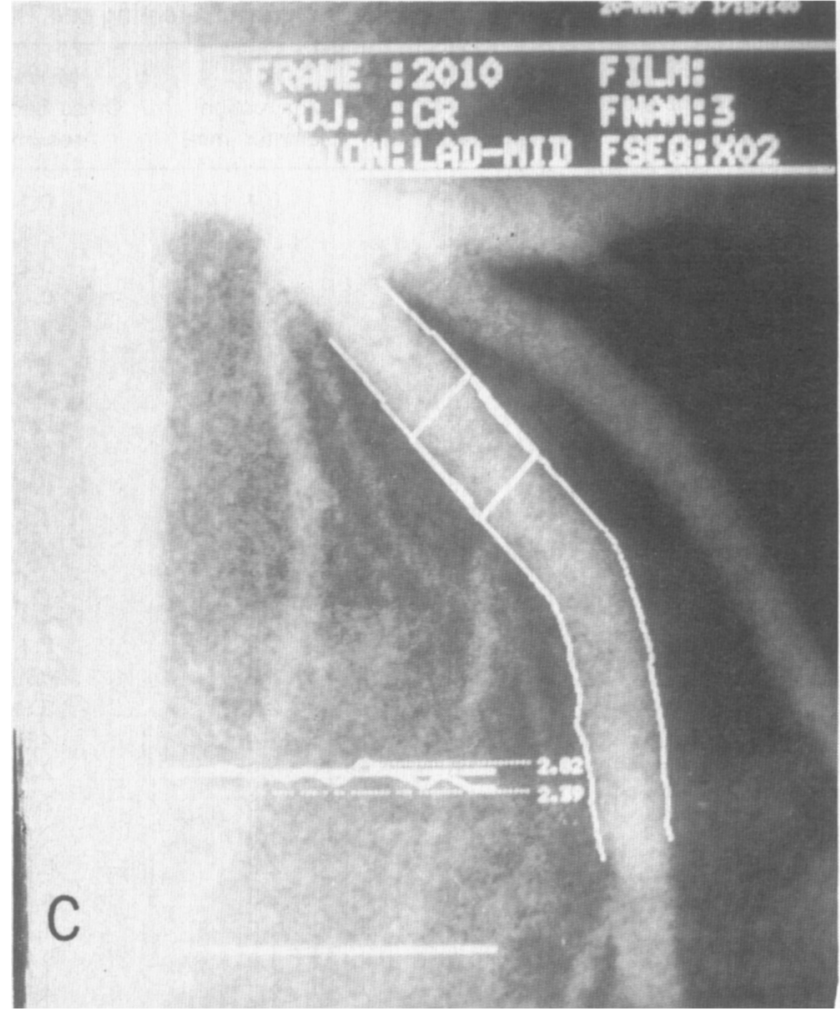

FIGURE 2. Angiograms of a left anterior descending coronary artery (cranial projection) before $(A)$ and after $(B)$ angioplasty, and immediately after stent implantation (C), with superimposition of the automated contours of the coronary artery segment of interest. Underneath are shown the diameter function of the detected contours of the coronary artery, the minimal lumen diameter (vertical Iine) and the interpolated diameter function (horizontal ine) from which the reference diameter is derived.

lation and before stent implantation. This $0.6-\mathrm{mm}$ change was greater than the average variability for this parameter and was therefore attributed to a diffuse spastic reaction. Among the 11 patients, 3 presented with an early thrombosis, 2 of them were successfully recanalized by thrombolytic therapy and PTCA; 6 were reinvestigated after a 3-month follow-up. The medications at the time of the initial and 3-month angiograms were identical and consisted of acetyl salicylic acid, dypiridamole, nitrates and calcium antagonists. The subcutaneous heparin was discontinued 6 weeks after the stent implantation. Repeat coronary angiography was performed 3 months after implantation in 6 patients ( 5 men, 1 woman).

\section{Methods}

Description of the stent ${ }^{11}$ : The stent is woven from a surgical-grade stainless-steel alloy formulated according to the specifications of the International Standards Organization. The prosthesis is geometrically stable, pliable and self-expanding. Its elastic and pliable properties are such that the diameter can be substantially reduced by moderate elongation. The prosthesis can be constrained on a small-diameter delivery 
catheter and, as the constraining membrane is progressively removed, the elastic device assumes its original (unconstrained) larger diameter. The constrained wire-mesh prosthesis is held at the distal end of the delivery catheter by a doubled-over membrane, the outer layer of which can be progressively withdrawn. Two radiopaque metal markers on the delivery catheter facilitate identification of the end of the prosthesis at the time of its deployment. The outer diameter of the loaded catheter system is $1.57 \mathrm{~mm}$ and prostheses able to expand to a diameter of $6.5 \mathrm{~mm}$ are mounted on this delivery device (Figure 1).

In this study, unconstrained stent diameter ranged from 3.0 to $3.5 \mathrm{~mm}$. The selection of stent sizes depended upon the size of the arterial segment, taking into consideration that the stent in its unconstrained form must have a diameter $0.5 \mathrm{~mm}$ larger than the stented vessel. The prosthesis consisted of 10 wire filaments each $0.08-\mathrm{mm}$ wide.

Quantitative coronary angiography: The determination of coronary arterial dimensions from $35-\mathrm{mm}$ cinefilm was performed with the computer-based Cardiovascular Angiography Analysis System. ${ }^{12-15}$ In essence, boundaries of the relevant coronary artery segment are detected automatically from optically magnified and video-digitized regions of interest of a selected cineframe. The absolute diameter of the stenosis (in $\mathrm{mm}$ ) is determined using the guiding catheter as a scaling device. The detected contours of the arterial and catheter segments are corrected for pincushion distortion. ${ }^{12,14}$ A computerized estimation of the original arterial dimension at the site of the obstruction is used to define the interpolated reference region. ${ }^{12,13}$ The interpolated percentage area stenosis and the minimal luminal cross-sectional area $\left(\mathrm{mm}^{2}\right)$ are then calculated and averaged from, if possible, at least 2, preferably orthogonal projections. The length of the lesion is determined from the diameter function on the basis of a curvature analysis.

The variability in obstruction diameter for short- 5 min), medium- ( $60 \mathrm{~min}$ ) and long-term (90 days) studies ranged from $0.22 \mathrm{~mm}$ for the short-term study to 0.36 $\mathrm{mm}$ for the long-term study. ${ }^{13}$ In the long-term study group, the lack of significant variation in the mean difference of the minimal lumen diameters suggested that no detectable progression or regression of atherosclerotic lesions had occurred over the 90-day period. Therefore, a change greater than the total measuremont variability of repcatod coronary cineangiography and quantitative analysis $(0.36 \mathrm{~mm}$ for obstruction diameter; i.e., 1 standard deviation of difference of duplicate measurements) was considered significant and indicative of restenosis.

Hemodynamic assessment: The theoretic pressure drop was calculated using the arteriogram and digital computation, according to well-known formulas described in the literature: ${ }^{16-18}$ Pgrad $=Q \cdot(R p+Q \cdot R t)$ where Pgrad is the theoretic transstenotic pressure decrease ( $\mathrm{mm} \mathrm{Hg}$ ) over the stenosis, Q the mean coronary blood flow $(\mathrm{ml} / \mathrm{s}), \mathrm{Rp}$ the Poiseuille resistance and $\mathrm{Rt}$ the turbulent resistance.

These resistances have been defined as follows:
$\mathrm{Rp}=\mathrm{C}_{1} \cdot($ length obstruction $) /$

(minimal cross-sectional area) ${ }^{2}$

where $\mathrm{C}_{1}=8 \cdot \pi \cdot($ blood viscosity $)$

with blood viscosity $=0.03 \mathrm{~g} / \mathrm{cm} \cdot \mathrm{s}$.

$\mathrm{Rt}=\mathrm{C}_{2}(1 /$ minimal cross-sectional area $-1 /$ normal distal area ${ }^{2}$

where $\mathrm{C}_{2}=$ (blood density $) / 0.266$

with blood density $=1.0 \mathrm{~g} / \mathrm{cm}^{3}$.

The theoretic transstenotic pressure drop was calculated for a theoretic coronary blood flow of $0.5,1$ and $3 \mathrm{ml} / \mathrm{s}$. The Poiseuille and turbulent contributions to flow resistance were determined from stenotic geometry assessed by quantitative coronary angiography.

Statistical analysis: Comparisons between postPTCA and post-stenting measurements and between post-stenting and 3-month follow-up measurements were carried out using the Student $t$ test for paired observations.

\section{Results}

Early assessment immediately after stenting (Figure $2 A-C$ ): The 11 patients were studied and a mean of

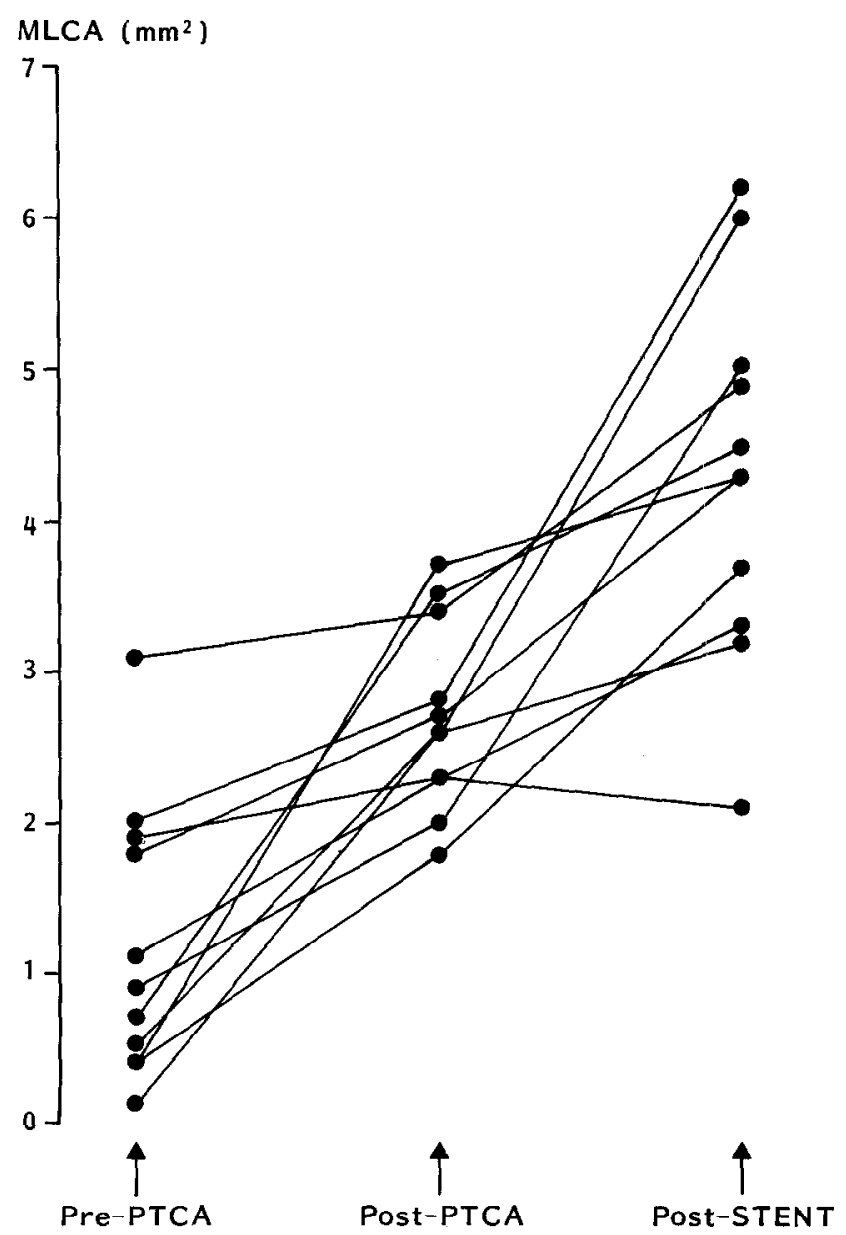

FIGURE 3. Changes in minimal luminal cross-sectional area (MLCA) between pre- (pre-PTCA) and post-angioplasty (postPTCA), and immediately after stent implantation (post-STENT). 

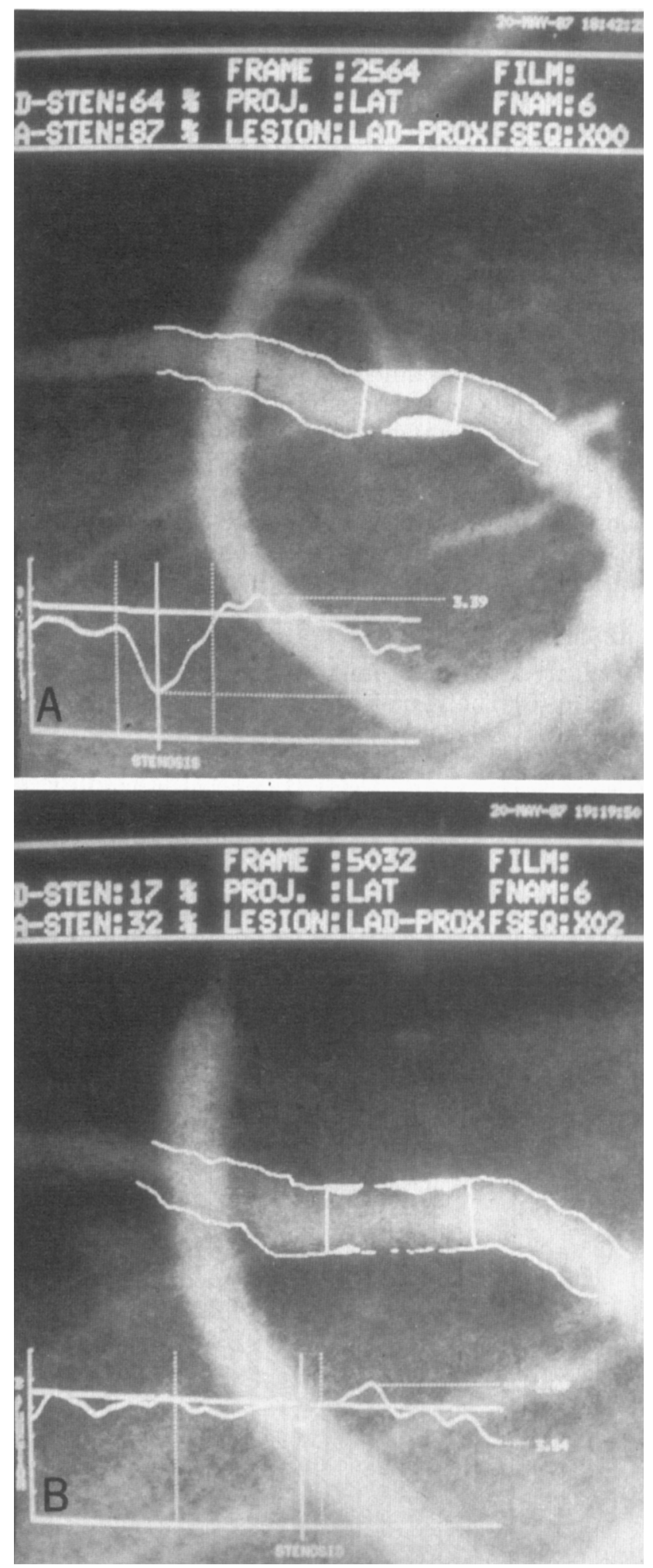

$2.0 \pm 0.4$ angiographic projections per lesion was analyzed. The morphologic and hemodynamic data (mean \pm standard error of the mean as well as the individual values of the parameters for each patient), are listed in Table I and II, respectively.

Stent implantation following PTCA resulted in an additional increase in minimal luminal cross-sectional area (Figure 3) and obstruction diameter, and a de-

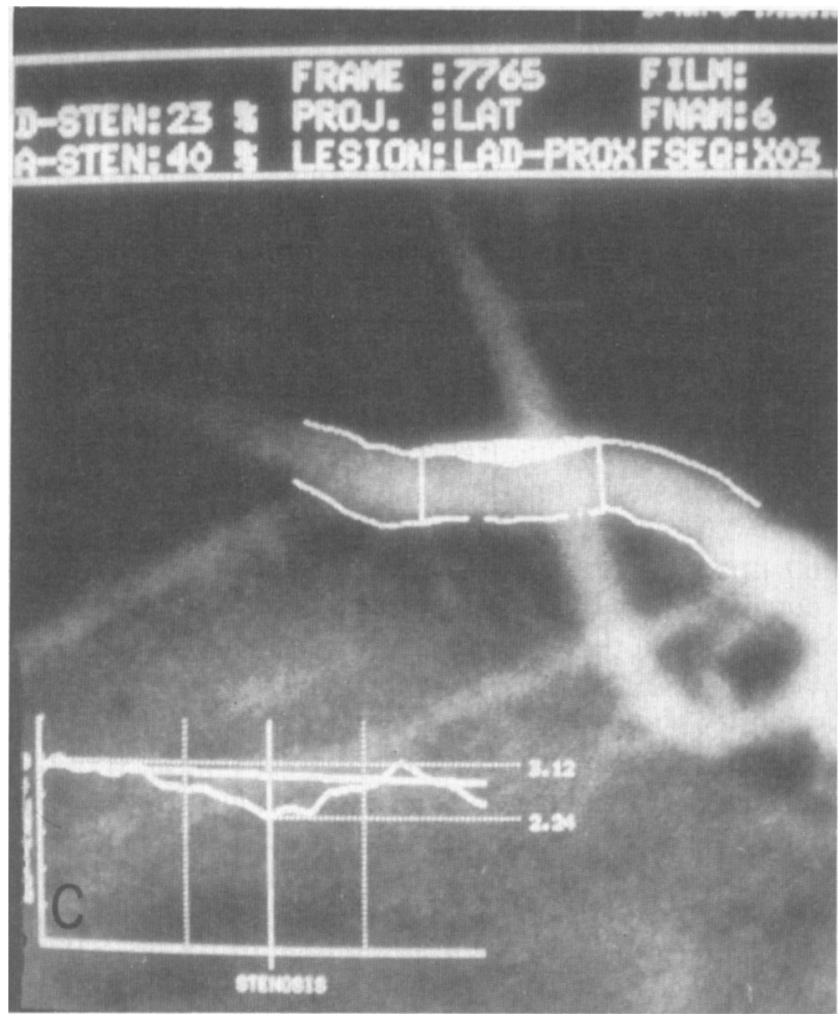

FIGURE 4. Angiograms of a left anterior descending coronary artery (lateral projection) before angioplasty $(A)$, immediately after stent implantation $(B)$ and after a 3-month follow-up $(C)$, with superimposition of the automated contours of the coronary segment of interest. Underneath are shown the diameter function of the detected contours of the coronary artery, the minimal lumen diameter (vertical line) and the interpolated diameter function (horizontal line) from which the reference diameter is derived.

crease in stenotic percentage area and percentage diameter. This morphological improvement was associated with a decrease in both the turbulent and Poiseuille resistance as well as the theoretic transstenotic pressure decrease for a theoretic flow of $1 \mathrm{ml} / \mathrm{s}$. It should be pointed out that the theoretic pressure gradient assumed a uniform reduction in the lumen over the entire length of the stenosis which may not always apply to the complex morphology of a stenotic lesion. However, these data suggest that, immediately after PTCA, the endoprosthesis has a dilating function in addition to its stenting role.

Late assessment after a three-month follow-up (Figure 4A-C): Six patients had repeat angiography at 3 months with a mean of $2.0 \pm 0.2$ angiographic projections per lesion. The morphologic and hemodynamic data (mean \pm standard error or the mean, as well as the individual values of the parameters for each patient) are listed in Table I and II, respectively.

The 3-month follow-up revealed a decrease in minimal luminal cross-sectional area (Figure 5), a decrease in obstruction diameter and an increase in stenotic percentage area and percentage diameter, when compared with the values recorded immediately after stent implantation. The obstruction diameter de- 
TABLE II Hemodynamic Results Immediately After Stenting and Three Months Later

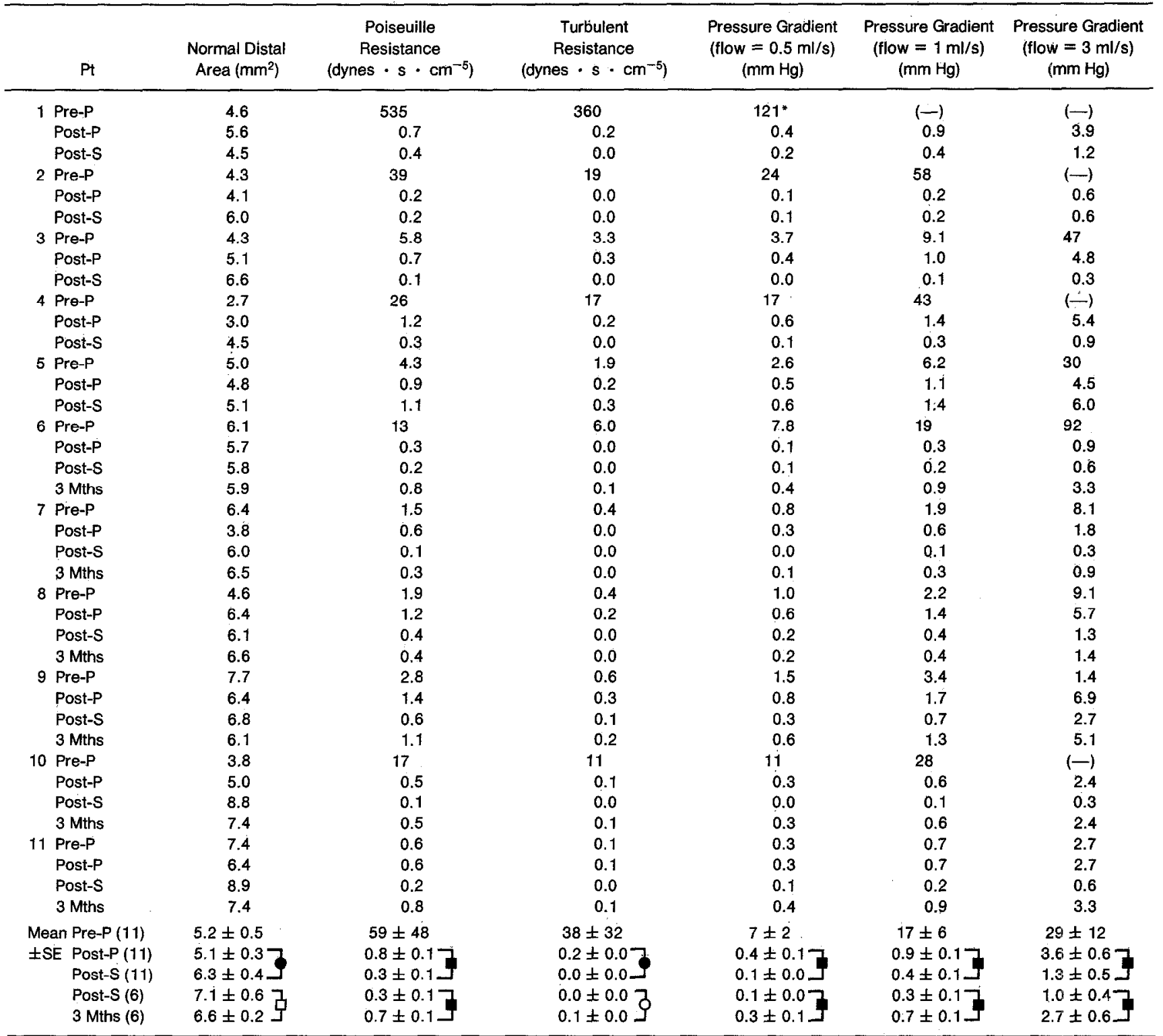

* Theoretic pressure decrease calculated for a theoretic blood flow of $0.20 \mathrm{ml} / \mathrm{s} ;(-)$ Theoretic pressure decrease greater than the mean aortic pressure. $\square=$ not significant; $=p<0.05 ; 0=p<0.01 ; \square=p<0.005$.

Mths = months; $\mathrm{P}=\mathrm{PTCA} ; \mathrm{S}=$ stent; $\mathrm{SE}=$ standard error.

creased from $2.4 \pm 0.1 \mathrm{~mm}$ to $2.0 \pm 0.1 \mathrm{~mm}$ and the stenotic percentage diameter increased from $23 \pm 4 \%$ to $34 \pm 3 \%$. The reduction in obstruction diameter was probably due to the neointimal proliferation, which theoretically should result in a diameter reduction of $0.2 \mathrm{~mm}$. The turbulent and Poiseuille resistance also increased significantly, but such an increase did not result in a hemodynamically significant pressure decrease over the stent for theoretic flow rates of 1 to 3 $\mathrm{ml} / \mathrm{s}$.

\section{Discussion}

A promising new approach to reduce the rate of restenosis is the implantation of an intravascular endoprosthesis. The principle of introducing intraarterial grafts percutaneously was first described by Dotter in
1969. ${ }^{5}$ During the last few years, variants of the original techrique using thermal-shaped memory alloys, ${ }^{4-19}$ expanding spring steel spirals, ${ }^{6}$ expanding stainlesssteel stents ${ }^{10}$ and expanding woven stainless-steel meshes ${ }^{7-9}$ have been reported in animal experiments.

Recently, intravascular stents have been implanted in humans to prevent occlusion and restenosis after PTCA. ${ }^{11}$ The endoprosthesis used in this first clinical series consisted of a new self-expandable stainlesssteel mesh. ${ }^{11}$ The early assessment immediately after stent implantation showed an additional morphologic improvement over the PTCA results, affecting both the stenotic and nonstenotic segments, which demonstrates the intrinsic dilating force of the stent. Sigwart et $\mathrm{a}^{11}$ have indicated that this prosthesis has an elastic radial force that tends to dilate the artery when the 


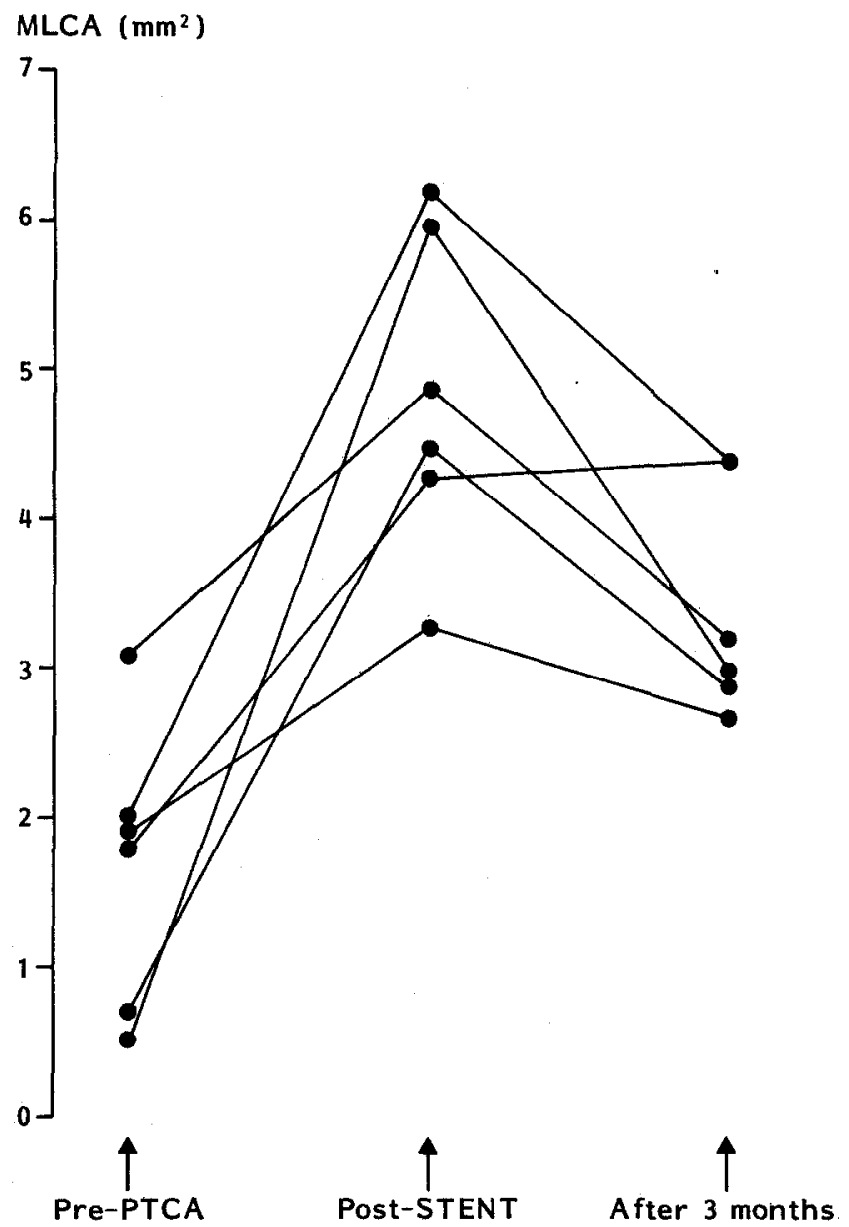

FIGURE 5. Changes in minimal luminal cross-sectional area (MLCA) between pre-angioplasty (pre-PTCA) and immediately after stent implantation (post-STENT) and after a 3-month follow-up.

vessel caliber is less than that of uncontrained stent diameter. Dilatation continues until an equilibrium is achieved between the circumferential elastic resistance of the arterial wall and the dilating force of the prosthesis. Previously, Wright et a ${ }^{10}$ showed that the expansile pressure depends on the recipient vessel diameter and on the intrinsic dilating force of the stent itself. The present study confirms-in human beingsthe dilating capacity of the stent.

In this study, changes in the nonstenotic segments are reflected in the significant increase observed in the interpolated reference diameter after stent implantation. In the interpretation of this result, 3 facts have to be considered with regard to the determination of the reference diameter.

First, the "interpolated" technique for the determination of the reference diameter incorporates in its computation all the individual diameter values of the proximal and distal coronary segments, which invariably include stented, but nonstenotic segments. Second, the stent size is selecled so as to have in its unconstrained state a diameter $0.5 \mathrm{~mm}$ larger than the vessel in which it is to be implanted, to ensure that the device will be securely anchored. Third, as the stent has a length ranging from 15 to $22 \mathrm{~mm}$, it is not surprising that the radial force exerted by the stent has a dilating effect on the nonstenotic segments included in the computation of the interpolated reference diameter.

All the long-term experimental studies have shown that in animals neointimal proliferation produces a covering of the stent's luminal surface. The time taken for the endothelialization process to cover the stent surface depends on the thickness of the wire filaments $^{7,8,10,11}$ ( 3 weeks for the prosthesis used in this study]. ${ }^{11}$ Neointimal thickening varies from 0.2 to 0.5 $\mathrm{mm}^{9,11}$ and depends on the diameter of the prosthesis. ${ }^{8}$ However, most investigators have not found important angiographic reductions in vessel diameter after stent implantation, 4,8,10,11 except for Dotter in his initial study ${ }^{5}$ In a previous study with conventional analysis of in vivo arteriograms, neointimal thickening was not described. ${ }^{9}$ In contradistinction, our study demonstrates that a small diffuse narrowing of the vessel's lumen is detectable by quantitative coronary angiography. In the present study, neointimal proliferation was estimated to produce a $0.200-\mathrm{mm}$ reduction in vessel diameter, corresponding to a $11 \pm 3 \%$ reduction in the stenotic percentage diameter. These results are consistent with animal studies on neointimal thickening, occurring after stent implantation.

\section{Appendix-Participating Centers and Collaborators}

Department of Clinical and Experimental Cardiology, CHRU Rangueil, Toulouse, France: J.P. Bounhoure, MD, A. Courtault, MD, F. Joffre, MD, J. Puel, MD, H. Rousseau, MD.

Catheterization Laboratory and Laboratory for Clinical and Experimental Image Processing, Thoraxcenter, Rotterdam, The Netherlands: K. Beatt, MRCP, M. v.d. Brand, MD, P.J. de Feyter, MD, P.G. Hugenholtz, MD, Y. Juilliere, MD, J.H.C. Reiber, PhD, J. Roelandt, MD, P.W. Serruys, MD.

Department of Cardiology, Hôpital Cardiologique, Lille, France: M.E. Bertrand, MD, J.M. Lablanche, MD.

Department of Clinical Measurement, National Heart Institute, London, U.K.: A. F. Rickards, MD, P. Urban, MD.

Division of Cardiology, Department of Mèdicine, CHUV, Lausanne, Switzerland: L. Kappenberger, MD, U. Sigwart MD.

\section{References}

1. Leimbruber PP, Roubin GS, Hollman J, Cotsonis GA, Meier B, Douglas JS, King III SB, Gruentzig AR. Restenosis after successful coronary angioplasty in patients with single-vessel disease. Circulation 1986;73:710-717.

2. Abela GS, Normann S], Cohen DM, Franzinj D, Feldman RL, Crea F, Fentech A, Pepine CJ, Conti CR. Laser recanalization of occluded atherosclerotic arteries in vivo and in vitro. Circulation 1985;71:403-411.

3. Choy DSI, Stertzer S, Rotterdam HZ, Sharrock N, Kaminow IP. Transluminal laser catheter angioplosty. Am I Gardiol 1982;50:1206-1208.

4. Gragg A, Lund G, Rysavy J, Castenada F, Castenada-Zuniga W, Amplatz K. Nonsurgical placement of arterial endoprostheses: a new technique using nitinol wire. Radiology 1983;147:261-263.

5. Dotter CT. Transluminally placed coil-spring endarterial tube grafts: longterm patency in canine popliteal artery. Invest Radiol 1969;4:329-332.

6. Maass D, Zollikofer CL, Largiader F, Senning A. Radiological follow-up of transluminally inserted vascular eridoprostheses: an experimental study using expanded spirals. Radiology 1984;152:659-663. 
7. Palmaz JC, Sibbitt RR, Reuter SR, Tio FO, Rice WJ. Expandable intraluminal graft: a preliminary study. Radiology 1985;156:73-77.

8. Palmaz JC, Sibbitt RR, Tio FO, Reuter SR, Peters JE, Garcia F. Expandable intraluminal vascular graft: a feasibility study. Surgery 1986;99:199-205. 9. PaImaz JC, Windeler SA, Garcia F, Tio FO, Sibbitt RR, Reuter SR. Atherosclerotic rabbit aortas: expandable intraluminal grafting. Radiology 1986; 160:723-726.

10.. Wright KC, Wallace S, Charnsangavej C, Carrasco GH, Cianturco C. Percutaneous endovascular stents: an experimental evaluation. Radiology 1985;156:69-72.

11. Sigwart U, Puel J, Mirkowitch V, Joffre F, Kappenberger L. Intravascular stents to prevent occlusion and restenosis after transluminal angioplasty. $N$ Engl I Med 1987;316:701-706.

12. Reiber JHC, Kooijman CJ, Slager CJ, Gerbrands JJ, Schuurbiers JHC, den Boer A, Wijns W, Serruys PW, Hugenholtz PG. Coronary artery dimensions from cineangiograms; methodology and validation of a computer-assisted analysis procedure. IEEE Trans Med Imaging 1984;MI-3:131-141.

13. Reiber JHC, Serruys PW, Kuoijman C], Wijns W, Slager CJ, Gerbrands JJ, Schuurbiers IHC, den Boer A. Hugenholtz PG. Assessment of short-, mediumand long-term variations in arterial dimensions from computer-assisted quantification of coronary cineangiograms. Circulation 1985;71:280-288.
14. Serruys PW, Reiber JHC, Wijns W, van den Brand M, Kooijman CJ, ten Katen H], Hugenholtz PG. Assessment of percutaneous transluminal coronary angioplasty by quantitative coronary angiography: diameter versus densitometric area measurements. Am I Cardiol 1984;54:482-488.

15. Zijlstra $F$, van Ommeren J, Reiber JHC, Serruys PW. Does quantitative assessment of coronary artery dimensions predict the physiological significance of a coronary stenosis? Circulation 1987;75:1154-1161.

16. Brown BG, Bolson E, Frimer M, Dodgo HT. Quantitative coronary arteriography. Estimation of dimensions, hemodynamic resistance and atheroma mass of coronary artery lesions using the arteriogram and digital computation. Circulation 1977;55:329-337.

17. Gould KL, Kelley KO, Bolson EL. Experimental validation of the quantitative coronary arteriography for determining pressure-flow characteristics of coronary stenosis. Circulation 1982;66:930-937.

18. Serruys PW, Wijns W, Reiber JHC, de Feyter $P$, van den Brand $M$, Piscione F, Hugenholtz PG. Values and limitations of transstenotic pressure gradients measured during percutaneous corondry angioplasty. Herz 1985; 10:337-342.

19. Dotter CT, Bushmann RW; McKinney MK, Rösch I. Transluminal expandable nitinol coil stent grafting: preliminary report. Radiology 1983; 147:259-260. 